\title{
Gagasan Ki Hajar Dewantara Tentang Kesenian dan Pendidikan Musik di Tamansiswa Yogyakarta
}

\author{
Diah Uswatun Nurhayati \\ PPPPTK Seni Budaya Yogyakarta
}

\begin{abstract}
The long journey of the idea of art education that has been done by Dewantara, until now apparently has not been able to make the education able to attract the attention of curriculum developers in Indonesia. Beginning with the name of art education, then became art education, handicraft and art, currently under the name Art culture and skills, the scope of which consists of music, dance, visual / painting, and theater. From the history of this art education curriculum, it can be seen that in fact Indonesia has not been able to come up with an idea of art education that can touch the aspects of creativity, taste, what initiative, and music education that can meet such competency standards. Things like this that have not been able to be formulated by educational developers, especially art, both at the central and regional levels. Therefore, the idea of art, especially music from Dewantara can be used as a reference as well as a guideline in developing arts education, arts or cultural arts in Indonesia, because the position of art in cultures around the world is always used as a measure to determine the low or high culture of a nation. Many opinions that culture is art and art is culture. Art is one of the most important parts of culture. Respecting the nobility of a nation is to study its art, because there is art there is respect, there is no art there is no appreciation for a nation.
\end{abstract}

Keywords: ideas, art, music

\begin{abstract}
Abstrak
Perjalanan panjang gagasan pendidikan kesenian yang sudah dilakukan Dewantara, sampai sekarang ternyata belum dapat membuat pendidikan tersebut mampu menarik perhatian para pengembang kurikulum pendidikan di Indonesia. Diawali dengan nama pendidikan kesenian, kemudian menjadi pendidikan seni, kerajinan tangan dan kesenian, saat ini dengan nama Seni budaya dan ketrampilan, yang ruang lingkupnya terdiri dari seni musik, tari, rupa/lukis, dan teater. Dari riwayat kurikulum pendidikan kesenian ini, dapat diketahui bahwa sebenarnya Indonesia belum dapat memunculkan ide pendidikan kesenian yang dapat menyentuh aspek cipta, rasa, karsa itu yang bagaimana, dan pendidikan musik yang dapat memenuhi standar kompetensi itu yang seperti apa. Hal-hal semacam inilah yang belum dapat dirumuskan oleh para pengembang pendidikan khususnya seni, baik di tingkat pusat maupun di tingkat daerah. Oleh sebab itu, gagasan tentang kesenian khususnya musik dari Dewantara dapat dijadikan acuan sekaligus pedoman dalam mengembangkan pendidikan seni, kesenian atau seni budaya di Indonesia, karena kedudukan kesenian di dalam kebudayaan di seluruh dunia selalu terpakai sebagai ukuran untuk menetapkan rendah tingginya kebudayaan dari sesuatu bangsa. Banyak pendapat bahwa kebudayaan adalah kesenian dan kesenian adalah kebudayaan. Kesenian salah satu bagian terpenting dari kebudayaan. Menghargai keluhuran bangsa adalah dengan mempelajari keseniannya, karena ada kesenian ada penghormatan, tidak ada kesenian tidak ada penghargaan terhadap suatu bangsa.
\end{abstract}

Kata kunci: gagasan; kesenian; musik

\section{Pengantar}

Keberadaan bidang pendidikan seni apapun jenis seninya, dalam struktur program pengajaran setiap pergantian kebijakan sistem pendidikan di Indonesia menjadi langkah awal untuk memikirkan bagaimana sebenarnya hakekat pendidikan seni itu sendiri. Perjalanan panjang dalam memberikan pengertian, baik tentang 
manfaat, nilai maupun fungsinya dalam membentuk karakter siswa, antara pengembang satu dengan lainnya sering kurang konsisten. Apalagi jika sudah membahas masalah substansi, kebijakankebijakan yang sudah berjalan baikpun semakin pudar dan sulit dipahami.

Sebagai bentuk upaya bersama untuk mengembangkan konsep pendidikan seni yang di dalamnya ada musik, tari, rupa dan teater, rasa-rasanya perlu melakukan pembenahan lebih serius terhadap kurikulum, metode maupun disain materi pada setiap jenjang pendidikan khususnya jenjang dasar dan menengah. Pendidikan seni yang diberlakukan dalam kurikulum 2013 saat ini merupakan bagian dari mata pelajaran Seni dan Budaya, yang secara konseptual memberikan tempat tidak hanya seni musik, seni rupa, seni tari dan seni teater, namun juga budaya secara universal dengan tujuan dapat melestarikan budaya daerah (lokal), menghargai keanekaragaman budaya Nusantara, mancanegara dan dunia, dengan tiga pilar yang harus diimplementasikan dalam KBM (kegiatan belajar mengajar), yaitu apresiasi, sensivitas dan kreativitas (Tim Pengembang Pendidikan Seni PPPG Kesenian, 2005).

\section{Gagasan tentang pendidikan Kesenian di} Tamansiswa

Menyadari bahwa pendidikan dan pengajaran seni atau disebut kesenian (sekarang dinamakan pendidikan seni dan budaya), diperlukan untuk menumbuhkembangkan budaya bangsa yang tidak hanya terdiri dari intelek atau pikiran. Dewantara mempunyai pemikiran tentang kesenian yang dapat dihubungkan dengan pendidikan dan pengajaran. Selain sebagai pemikir kesenian, Dewantara juga sebagai praktisi pendidikan kesenian yang menguasai berbagai cabang seni seperti tari, gambar, musik, karawitan Jawa dan sebagainya. Upaya untuk mengamati tentang beberapa kesenian tersebut, yang penting diketahui dalam pendidikan kesenian adalah kata 'seni' itu sendiri, yaitu:

Seni adalah segala perbuatan manusia yang timbul dari hidup perasaannya dan bersifat indah. Seni itu keindahan yang dibuat oleh manusia. Jadi keindahan alam tidak termasuk di dalamnya, walaupun ada hubungannya, bahkan bolehlah kita tetapkan bahwa keindahan alam itu selalu mempengaruhi rasa keindahan manusia dan senantiasa menjadi sumber keindahan (Dewantara, 2004: 330).

Keterangan singkat tentang kesenian dapat dijelaskan bahwa membuat kesenian itu bukan tenaga yang seketika, tetapi buah dari kehendak yang pasti serta sudah dipikirkan dengan matang. Kesenian itu juga tidak hanya timbul dari perasaan saja, namun berhubungan dengan pikiran. Sebelum menetapkan kesenian-kesenian apa saja yang dapat dipakai sebagai alat pendidikan dan pengajaran tersebut, terlebih dahulu akan diulas kedudukan dan peranan kesenian di dalam hidup dan penghidupan manusia pada umumnya. Kesenian menurut Dewantara dapat diartikan sebagai karya manusia yang mengetengahkan keindahan dan diciptakan manusia berupa produk berbagai macam yang dapat memberi nikmat, yaitu nikmat dalam batas panca indra sampai lebih jauh lagi menyentuh kejiwaan yang dalam (Dewantara, Ibid: 351353).

Berdasar pendapat Dewantara, kesenian merupakan bagian dari kebudayaan yang sangat luas jangkauan dan ruang lingkupnya sehingga tidak dapat dilepaskan dari kehidupan manusia. Kedudukan kesenian di dalam kebudayaan di seluruh dunia selalu terpakai sebagai ukuran untuk menetapkan rendah tingginya kebudayaan dari sesuatu bangsa. Bahkan banyak yang menyimpulkan bahwa kebudayaan adalah kesenian dan kesenian adalah kebudayaan. Dengan demikian, kesenian dapat dianggap bagian terpenting daripada kebudayaan. Pada umumnya, 
menghargai keluhuran bangsa adalah dengan mempelajari keadaan kesenian rakyat, karena ada kesenian ada penghormatan, tidak ada kesenian tidak ada penghargaan terhadap suatu bangsa. Sebagai langkah pemikiran tentang kesenian dalam kebudayaan, Dewantara mengemukakan kesenian Indonesia sebagai berikut:

Kesenian bangsa Indonesia kini belum ada; yang ada hanya kesenian daerah; apabila kebangsaan Indonesia yang kini kita kejar jadinya, sudah terbentuk, maka seni Indonesia akan jadi juga. Adapun bentuknya seni Indonesia itu akan bersifat baru, tetapi tidak akan meninggalkan dasar-dasarnya kebudayaan dari berbagai daerah Indonesia. Kesenian Indonesia akan terbentuk dengan memakai atau mempergunakan segala puncak-puncak kesenian dari keseniankesenian daerah. Sesudah kebangsaan Indonesia termasuk, maka daerah-daerah masih akan mempunyai sifat-sifat yang berdasarkan pada teori, bahwa kesenian dan kebudayaan lainnya itu selalu hidup meneruskan garis hidup lama, selalu makin lama makin berdekatan dengan kesenian dari golongan-golongan lain, dan akhirnya bercampur juga tetapi masih nampak kekhususannya masing-masing (kontinyukonvergen-konsentris) (Dewantara, Ibid: 334).

Pemikiran kesenian Indonesia yang mengarah kepada keanekaragaman budaya secara jelas pada pernyataannya tentang 'segala puncak-puncak kesenian dari kesenian-kesenian daerah'. Pernyataan tersebut juga tercermin dalam daftar pengajaran umum yang memasukkan kesenian kebangsaan sebagai pengajaran yang dapat mempersatukan dan memperkuat kebudayaan bangsa, menumbuhkan semangat kebangsaan yang sehat dan kuat (tidak menyalahi hukum adab kemanusiaan). Sedangkan pelajaranpelajarannya diambil dari sumber-sumber keagamaan, adat-istiadat, kesusilaan, kesenian, sejarah dan sebagainya, yang mengandung pelajaran keadaban pada umumnya. Adapun konsep tentang kesenian kebangsaan dikemukakan sebagai berikut:

a. Kesenian kebangsaan, yang mudah atau dapat diberikan dalam kelas atau secara umum pada perguruan, dapat dipergunakan untuk menghaluskan budi pekerti serta untuk menebalkan rasa kebangsaan;

b. Perlu agaknya diadakan panitia untuk menyelidiki kesenian-kesenian apakah yang patut diberikan pada semua sekolah di seluruh Indonesia, dan apakah yang hanya penting bagi daerah masingmasing;

c. Kesenian kebangsaan yang dapat dipelajarkan di perguruan ialah seni suara, seni lukis, seni sastra, seni tari, seni sandiwara dan permainan kanak-kanak yang bersifat kesenian diantara 'Natur dan Kultur';

d. Akademi Kesenian perlu diadakan di daerah-daerah yang jadi pusat-pusat kesenian; demikian pula adanya sekolahsekolah kesenian khusus, kunstambachtsschool, kursus-kursus kesenian dan sebagainya di tempat-tempat yang jadi pusat-pusat kesenian khusus itu (Dewantara, Ibid: 345-346).

Sebenarnya masih banyak keseniankesenian kebangsaan yang sampai saat ini masih relevan dikembangkan. Di samping mengembangkan kesenian-kesenian yang merupakan peninggalan nenek moyang yang bermutu tinggi, akan lebih baik jika diberikan kepada anak-anak sehingga dapat mengembangkan dan melestarikan kesenian dan persatuan bangsa, walaupun dengan bahan-bahan dari kebudayaan bangsabangsa lain. Jika tidak dapat diberikan di dalam pengajaran secara klasikal, dapat diberikan di luar jam pengajaran. Dalam usahanya untuk mendekatkan anak didik kepada pelestarian budaya dan persatuan bangsa, Hadisukatno melalui pelajaran 
kesenian di perguruan Tamansiswa mengemukakan:

Jika terjadi kebudayaan persatuan, maka diprioritaskan kepada pertumbuhan dan percampuran. Pada hakekatnya, soal kebudayaan tidak dapat dipaksakan, kesemuanya akan jadi dengan sendiri karena saling pengaruh mempengaruhi, dan karena persesuaian pertumbuhan. Ini tidak berarti bahwa kita pasif dalam usaha menuju persatuan ini, bahkan sebaliknya; hanya pangkal usahanya harus dari kebudayaan daerah masing-masing, agar pertumbuhannya selalu bersambungan (continue), dan akhirnya baru menuju convergentie dengan kebudayaan dunia (Hadisukatno, 1980: 156).

Dari berbagai konsepsi dan pemikiran tentang pendidikan kesenian kebangsaan, secara tidak sengaja telah mendekatkan anak kepada kebudayaan sendiri, yang berarti juga mendidik anak itu menurut kodratnya dengan keadaan alam sekitarnya. Meskipun kebudayaan sendiri belum berwujud nyata, tetapi daerah-daerah yang merupakan bagian-bagian dari negara Indonesia banyak mempunyai corak dan bahan-bahan untuk dijadikan dasar dalam mendidik anak. Dari pangkal inilah dapat memupuk perkembangan jiwa anak, dan dari pangkal ini pulalah dapat dikembangkan cita-cita pendidikan kesenian kebangsaan yang bermuara pada keanekaragaman budaya Indonesia. Demi menghindari salah tafsir, bahwa sesuatu bangsa hanya dapat kuat dan berharga dalam pergaulan dunia, jika bangsa itu mempunyai corak yang sesuai dengan kodrat dan watak pembawaanya, yang terlahir berupa kebudayaan. Artinya, bangsa Indonesia tidak menolak pemasukan dan pencampuran kebudayaan lain bangsa, tetapi justru sebaliknya, bangsa Indonesia tidak segan-segan mengoper bahan-bahan kebudayaan bangsa lain untuk memperkaya kebudayaan, dengan corak dan dasar dari budaya bangsa sendiri.
Fungsi penting kesenian khususnya gamelan dan tari Jawa, mengakibatkan Dewantara memasukkan ke dalam kurikulum wajib Tamansiswa, seperti pernyataan berikut:

Pelajaran gendhing tidak hanya diperlukan untuk mencari pengetahuan serta kemampuan memainkan gendhing saja, tetapi penting juga untuk membangkitkan hidup kebatinan, karena gendhing selalu menuntun rasa berirama (rhythmisch gevoel), menghidupkan rasa keindahan (aesthetisch gevoel), mengheningkan rasa kesusilaan (ethisch gevoel). Di samping itu, untuk menanamkan spiritual di Jawa, para pendeta dan wali memperhatikan budaya gendhing. Banyak yang ikut membangun bentuk-bentuk gendhing dan kidung seperti Sunan Kalijaga, Sunan Giri, Sultan Agung dan sebagainya. Sementara di Barat, para pemuka agama dan gereja menerapkan daya kekuatan gendhing, sebagai pembuka rasa kebatinan (religius gevoel), pengasah budi pekerti (karakter vorming), yang menjadi dasar tajamnya cipta, halusnya rasa dan kuatnya karsa (Dewantara, Ibid: 41-42); (Sumarsam, 2003:167-169).

Berdasar penjelasan tentang fungsi kesenian, sudah selayaknya soal kesenian yang ditempatkan pada lingkaran 'Pancadharma' Tamansiswa, dipakai juga dalam pendidikan di Indonesia, karena kesenian yang dipakai sebagai alat pendidikan di Tamansiswa tersebut bermaksud mempengaruhi perkembangan jiwa anak-anak kearah keindahan pada khususnya, namun keindahan di dalam rangkaiannya dengan keluhuran dan kehalusan, sehingga layak bagi hidup manusia yang beradab dan berbudaya. Kesenian juga perlu disandarkan pada hidup kebangsaan dalam arti yang luas, tidak bertentangan dengan perikemanusiaan dan tidak melanggar hukum-hukum. Menyadari hal tersebut, Tamansiswa pernah menyelenggarakan permusyawaratan khusus membahas masalah kesenian yang 
berlangsung dari tanggal 13 - 18 Mei tahun 1954, dibuka oleh Menteri P dan K Moh. Yamin (Nayono, 1992: 248-249).

Musyawarah menghasilkan putusan berupa tujuan, cara dan usaha. Usaha yang dilakukan permusyawaratan Pendidikan Kesenian meliputi:

a. Diusahakan agar ditiap cabang, pendidikan ekspresi tidak diabaikan (permainan anak-anak, bernyanyi, menggambar, pekerjaan tangan);

b. Diusahakan agar di tiap cabang anakanak dapat bergiat di lapangan kesenian melalui PPTS;

c. Diusahakan agar di tiap cabang mengadakan hubungan yang erat dengan badan-badan kesenian dan para seniman, serta member kesempatan kepada mereka untuk mengadakan latihan-latihan, ceramah dan diskusi di rumah perguruan;

d. Diusahakan agar di tiap cabang mengadakan badan-badan kesenian yang diselenggarakan oleh para pamong, murid dan peminat dari dunia luar;

e. Diusahakan agar di tiap cabang lambat laun dapat memberi pendidikan kesenian yang meliputi segala cabang kesenian;

f. Diusahakan agar diadakan Taman Guru Kesenian dengan Laboratorium Kesenian;

g. Diusahakan agar Majlis Luhur Bagian Pendidikan dapat memberikan bimbingan kepada cabang-cabang di dalam lapangan pendidikan kesenian, baik secara langsung maupun melalui suatu badan yang bertanggung jawab kepadanya;

h. Diusahakan agar diadakan majalah bulanan yang khusus mengenai penddikan kesenian dan kebudayaan, atau sedikit-dikitnya di 'Pusara' disediakan ruangan yang khusus untuk maksud tersebut (Nayono, Ibid: 250).

Dari usaha permusyawaratan pendidikan kesenian di atas, berarti Tamansiswa pernah mengawali untuk menggagas kedudukan pendidikan kesenian dalam sistem pendidikan masa itu. Akan tetapi, setelah Dewantara wafat pada tahun 1959 permusyawaratan tersebut sudah tidak diadakan lagi. Namun demikian, pendidikan kesenian yang diajarkan di sekolah-sekolah umum masih mengadopsi konsep-konsep Tamansiswa. Pendidikan kesenian tersebut hanya berubah nama seperti: Pendidikan Seni, Seni Suara, Kerajinan tangan dan kesenian, namun semuanya menggunakan ajaran-ajaran yang pernah dilakukan Tamansiswa, seperti nampak dalam foto di bawah ini.

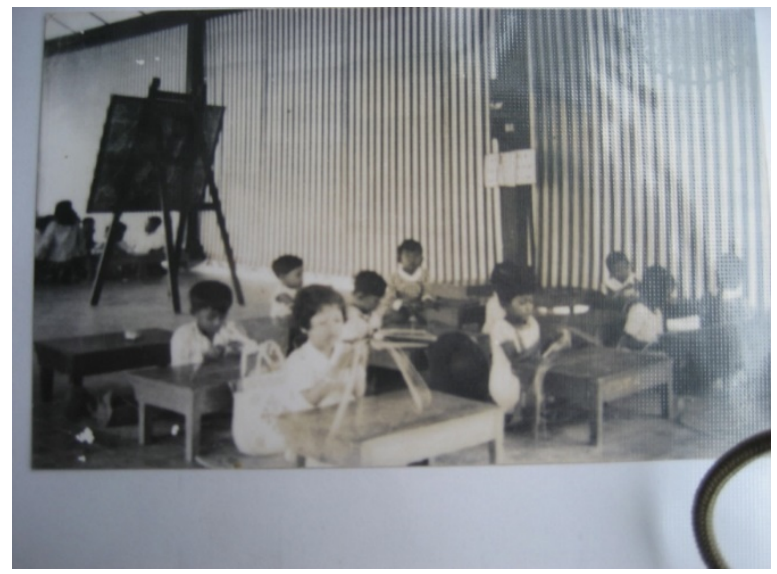

Gambar 1: Pelajaran Kesenian ketrampilan, melukis (Sumber: Museum Dewantara)

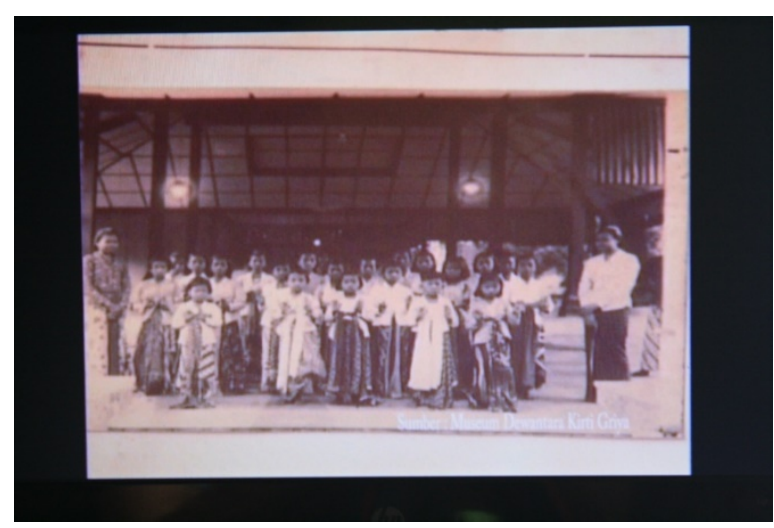

Gambar 2: Pelajaran kesenian musik dan tari (Sumber: Museum Dewantara)

\section{Pembahasan}

Sejak awal berjuang Dewantara masuk organisasi gaya Barat, karena melalui organisasi inilah bentuk perlawanan rakyat terhadap penjajahan yang paling mungkin pada awal 1910-an. Akan tetapi, setelah di 
asingkan ke negeri Belanda, Dewantara belajar banyak bahwa organisasi tanpa pencerdasan dan kesadaran rakyat adalah makna kosong. Dari sinilah arah perjuangan Dewantara berubah. Perubahan itu secara radikal ditunjukkan dengan mendirikan sekolah bernama Taman Siswa pada 1922, karena pendidikanlah yang dapat membuat rakyat sadar akan adanya sebuah penindasan.

Beberapa pokok tulisan tentang puncak-puncak kebudayaan yang ada di majalah, surat kabar maupun buku yang terbit tahun 1920-1930-an, dapat menjadi sarana penyebar utama dan pendukung diseminasi pemikiran tentang pendidikan musik di Indonesia. Tulisan-tulisan tersebut diterbitkan setelah Dewantara menjalani hukuman pengasingan di negeri Belanda, yang secara tegas menolak pendidikan yang terlalu mengutamakan intelektualisme dan mengorbankan aspek kerohanian atau jiwa anak didik. Menurut Dewantara, pendidikan yang ditawarkan oleh pemerintah kolonial hanya akan membuat pribumi lupa akan kebudayaannya dan membuat pribumi menjadi tenaga terampil bagi kepentingan pemerintah kolonial. Berkaitan hal tersebut, Dewantara akhirnya memutuskan untuk mendirikan sebuah sekolah yang menawarkan pendidikan berorientasi kepada kebudayaan timur dan mengedepankan nilai-nilai kultural yang disertai dengan kekuatan intelektual. Konsep pendidikan tersebut memadukan pendidikan gaya Eropa yang modern dengan seni-seni Jawa tradisional (Ricklefs, 2005: 366 - 368).

Ketika terjadi persentuhan dua kultur, akibat penting yang ditimbulkan adalah bangkitnya nasionalisme Indonesia. Berbekal nasionalisme ini, musik Jawa dan musik tradisi lainnya berlanjut hidupnya. Dalam usaha mendefinisikan kebudayaan nasional Indonesia, akhirnya Dewantara mengusulkan bahwa kebudayaan nasional harus mewakili puncak-puncak kesenian daerah. Sebagai contoh adalah gamelan Jawa, yang merupakan puncak dan paling menonjol dari daerah Jawa. Akan tetapi, beberapa nasionalis non-Jawa tidak dapat menerima pemikiran tentang kebudayaan nasional tersebut, akibatnya masalah tentang kebudayaan nasional menjadi polemik tersendiri. Dengan latar belakang nasionalisme ini, akhirnya diputuskan melalui Undang-undang nomor 32 bahwa: kebudayaan nasional Indonesia adalah puncak-puncak kebudayaan daerah diseluruh Indonesia, baik yang asli maupun yang baru, yang berjiwa nasional. Berjiwa nasional maksudnya adalah untuk membatasi agar jangan sampai bangsa Indonesia hanya meng-copi kebudayaan asing tetapi menyesuaikan dengan kebudayaan bangsa Indonesia sendiri.

Pada saat terjadi polemik dan perdebatan tentang kebudayaan nasional, diredam pemberlakuan Kulturkammer, yaitu suatu peraturan di dalam berkesenian, dimana Jepang melarang segala seni yang bukan berasal dari Indonesia, terkecuali musik klasik, dan memuja-muja ketimuran (Pasaribu, 1995: 35). Selain musik klasik, musik keroncong juga diperbolehkan, tetapi nyanyian yang mengarah ke barat harus dibuang. Musik Hawaian, musik dansa, jazz dan musik-musik barat lainnya dilarang oleh Jepang. Kedatangan Jepang membawa perubahan di dalam kehidupan musik. Timbulnya nasionalisme dalam bermusik dapat digambarkan dengan mengamati banyak tulisan yang dimuat oleh para ahli kebudayaan dalam majalah-majalah saat itu.

Nasionalisme yang mencuat pada masa Budi Utomo, pada jaman Jepang muncul kembali. Kehidupan musik menjadi sangat berarti karena rakyat menjadi cinta kepada tanah air yang disebabkan oleh lagulagu propaganda dan adanya Keimin Bunka Shidoso. Dengan pemaksaan melalui Kulturkammer tersebut, muncul kesadaran masalah kebangsaan di bidang musik. Bangsa Indonesia diharuskan untuk 
menciptakan lagu-lagu Indonesia, sehingga muncul lagu-lagu dengan syair yang indah, memuja tanah air yang subur, makmur, damai dan sejahtera (Pasaribu, Ibid: 34-36).

Kaitannya dengan lagu-lagu
Indonesia ini, sebelum diasingkan ke Belanda, Dewantara dalam perjalanannya pernah menulis surat ke tanah air untuk mempersiapkan lagu kebangsaan Indonesia yang mengilhami WR. Soepratman menciptakan lagu Indonesia Raya. Soekarnopun akhirnya menunjuk Dewantara menjadi ketua tim penyempurna lagu kebangsaan Indonesia. Karena selama dalam pengasingan di Belanda Dewantara mempelajari musik Barat, oleh sebab itu pada saat ada pemaksaan Kulturkammer dari Jepang untuk cinta kepada tanah air, perhatian pada bidang tersebut sangat besar, sehingga Dewantara memerintahkan kepada pamong Tamansiswa Hadisukatno untuk belajar musik kepada Kusbini (seperti dituliskan oleh Hadisukatno dalam buku dolanan anak). Sebelumnya dia juga pernah secara khusus mempelajari teori musik Cheve dengan menggubah lagu Kinanthi sandung untuk komposisi piano karya Mangkunegoro IV yang dipentaskan di konservatori kerajaan Belanda (Poeze, 1950: 107-110).

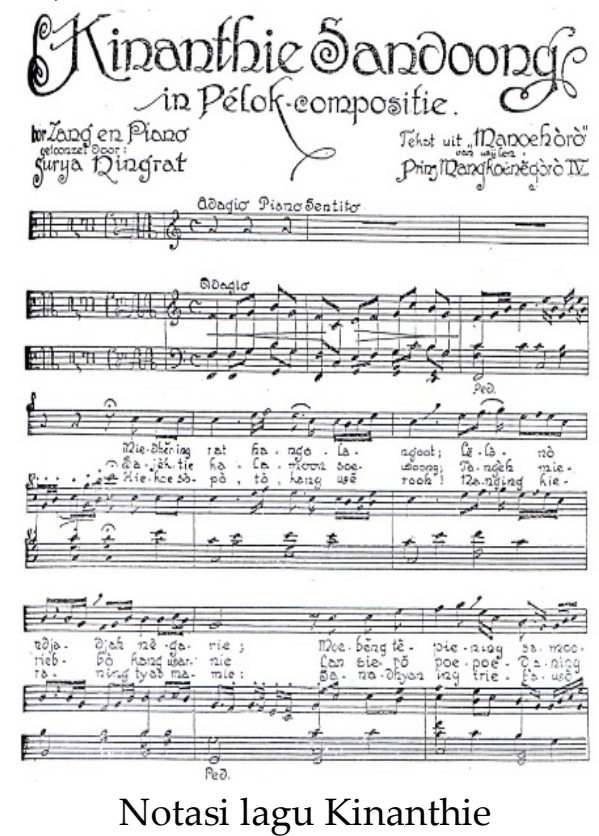

Lagu Kinanthi sandung di atas, dinyanyikan mahasiswa konservatori dengan baik karena ditulis dengan notasi balok, sehingga tidak ada yang kesulitan dalam membaca nada-nadanya. Dewantara juga mengajukan beberapa panduan praktis dalam mendidik musik sejak masih anakanak. Dalam artikel yang berjudul Nationale Frobelschool. Cursus oentoek mempeladjari permainan dan njanjian anak, secara jelas Dewantara mementingkan pelajaran permainan dan nyanyian bagi anak, karena pelajaran permainan dan nyanyian dapat berguna untuk mendidik rasa kebatinan anak (wawancara dengan Priyo Dwiarso tanggal 7 Pebruari 2009). Kemudian pada tahun 1926, Dewantara juga menerapkan metode pembelajaran seni musik yang dinamai dengan metode Sari Swara.

Menurut Priyo Dwiarso, Dewantara belajar musik Barat selain untuk mengenalkan budaya bangsa sendiri, juga ingin mendapatkan kepastian bahwa musik Jawa yang bersifat lokal, sepadan dengan musik klasik Barat serta mempunyai nilainilai musikal yang dapat diterima secara universal (wawancara, tanggal 12 Oktober 2009). Setelah sampai ke Indonesia tahun 1919-an, usaha untuk untuk mencapai seni suara yang 'satu' dan 'me-nasional-kan' musik-musik daerah, selalu dilakukan. Percobaan demi percobaan dijalankan, ada yang berhasil baik, ada yang tidak berhasil. Sindoesawarno mengatakan bahwa, usahausaha untuk mementingkan seni suara daerah namun dapat dipahami dan dipakai di dalam perguruan-perguruan di seluruh Indonesia mulai dipikirkan melalui perguruan yang kemudian didirikannya pada tahun 1922, yaitu Tamansiswa melalui pengajaran muziekler (Sindoesawarno, 1981: 140-141).

Meskipun banyak mendapat pendidikan Barat, baik pendidikan secara umum maupun pendidikan musik, Dewantara merupakan seorang tokoh yang 
humanis. Selain itu, dari pendidikan Jawanya, Dewantara juga tidak menjadi seorang Jawa centris. Hal ini dibuktikan dengan dilepaskannya gelar kebangsawanan dan nama Jawanya, Dewantara bukanlah seorang Jawa centris. Pemahamannya bahwa seseorang haruslah bekerja keras untuk melayani dan bukan untuk dilayani juga menjadi bukti lainnya bahwa Dewantara adalah seorang sosok yang mengombinasikan nilai-nilai luhur dua kultur, yaitu Barat dan Jawa.

Dari beberapa uraian yang telah dikemukakan di atas, karena tujuan tulisan ini untuk mengetahui pemikiran Dewantara tentang pendidikan musik, maka melalui pelajaran muziekleer gagasan tersebut dapat dibuktikan. Pelajaran muziekleer sebenarnya menyimpan pesan budaya yang tinggi, yaitu dapat mendewasakan anak secara kultural, sehingga anak tidak menjadi xenophobis (memusuhi budaya lain). Beberapa fakta juga sudah membuktikan bahwa pelajaran muziekleer dapat dipakai sebagai alat pendidikan. Agar lebih mengetahui pemikiran tentang pelajaran muziekleer, yaitu pengetahuan musik baik barat maupun timur, berikut dokumentasi pementasan kegiatan koor (menyanyi):

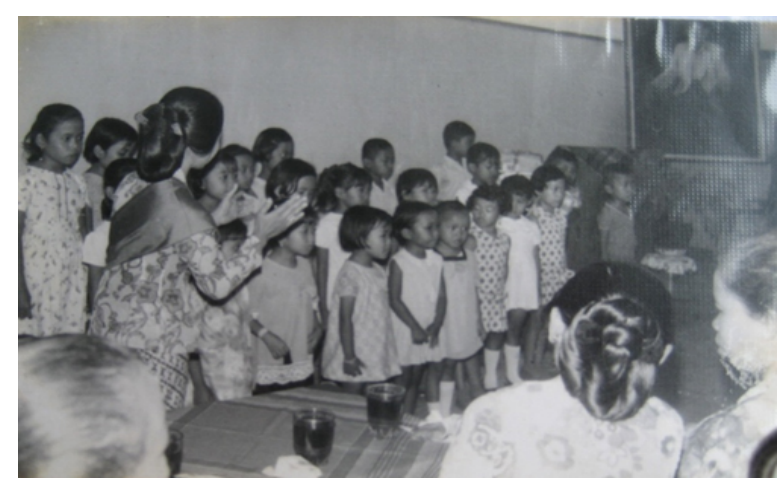

Gambar 3: Pelajaran Menyanyi (Sumber: Museum Dewantara KG)

\section{Penutup}

Banyak gagasan Dewantara tentang pendidikan, politik, budaya maupun bidang lain yang sudah ditulis dalam buku, majalah, surat kabar dan media cetak lainnya. Namun gagasan yang belum ditulis secara mendalam adalah gagasannya tentang kesenian, yang salah satu cabang seninya adalah musik, baik musik barat maupun tradisi (Jawa). Gagasan-gagasan tentang kesenian pernah ditekuni dengan melibatkan para tokoh-tokoh seniman, namun tidak ada kelanjutannya sehingga sampai sekarang bangsa Indonesia selalu mengadopsi atau mengacu kepada pendidikan seni dari barat. Padahal pemikiran atau gagasan Dewantara memiliki kelebihan dibanding pemikiranpemikiran dari luar yaitu dengan menyesuaikan budaya bangsa sendiri. Seperti diketahui bahwa kesenian merupakan bagian dari kebudayaan yang sangat luas jangkauan dan ruang lingkupnya sehingga tidak dapat dilepaskan dari kehidupan manusia. Kedudukan kesenian di dalam kebudayaan di seluruh dunia selalu terpakai sebagai ukuran untuk menetapkan rendah tingginya kebudayaan dari sesuatu bangsa. Bahkan banyak yang menyimpulkan bahwa kebudayaan adalah kesenian dan kesenian adalah kebudayaan. Dengan demikian, kesenian dapat dianggap bagian terpenting daripada kebudayaan.

Gagasan selanjutnya adalah pendidikan musik yang sudah dirancang Dewantara 90 tahun yang lalu. Dari gagasan yang sudah dirancang saat itu diharapkan sistem pendidikan di Indonesia dapat memiliki paradigma pendidikan seni musik beserta metode pembelajaran yang komprehensif. Meskipun konsep Dewantara saat itu belum diakui keberadaannya, bahkan tidak sedikit yang meragukannya, namun pemikiran tentang musik barat dan timur dalam muziekleer dapat berjalan berdampingan perlu ditindaklanjuti. Sebenarnya pengembang kurikulum tingkat pusat sudah menyediakan tempat untuk menyelenggarakan pendidikan musik meskipun dengan sebutan yang berbedabeda, namun karena pelaksana pendidikan dalam hal ini guru lebih mementingkan hasil daripada proses, maka tujuan pendidikan 
yang menuntut aspek cipta, rasa, karsa belum membuahkan hasil. Melalui gagasan dalam bidang musik, langkah yang perlu dicermati adalah kemampuan untuk menyikapi, salah satunya adalah dengan membuat seperangkat atau menyediakan metode pendidikan musik untuk guru sebagai penyalur langsung buah pemikiran Dewantara.

\section{Referensi}

Dewantara, Ki Hajar, (2004) Pendidikan (bagian pertama), Majlis Luhur Persatuan Tamansiswa, Yogyakarta (2004), Kebudayaan (bagian kedua), Majlis Luhur Tamansiswa. Yogyakarta. (1964), Serat Sari Swara, Penerbit Pradnjaparamita, Djakarta.

$$
\text { (1959), Taman Indrya, }
$$

Kindergarten, Majlis Luhur Persatuan Tamansiswa, Yogyakarta. Fudyartanta, (1998). Mengenal Tamansiswa, Sejarah dan Pendidikan Sistem Among, Majlis Luhur Persatuan Tamansiswa, Yogyakarta.

Hadisukatno, Ki. (1970), "Permainan Kanakkanak sebagai Alat Pendidikan" dalam Buku Peringatan Taman Siswa 1922-1952. Majlis Luhur Persatuan Taman Siswa, Yogyakarta.

Karl-Edmund Prier sj. (1991), Sejarah Musik jilid I, II, PML, Yogyakarta.

Kamajaya, Karkono, 1992. Dasar dan watak nasionalisme Indonesia. Peringatan 70 tahun Tamansiswa 1922-1992. Pendidikan dan pengembangan SDM, MPLT. Yogyakarta.

Nayono, Ki, (1992), "Pendidikan Kesenian" dalam 70 Tahun Tamansiswa 19221992, Majlis Luhur Persatuan Tamansiswa, Yogyakarta.
Pasaribu, Amir. (1986), Analisis Musik Indonesia, PT. Pantja Simpati, Jakarta.

(1953), Riwayat Musik dan Musisi, Penerbit Djambatan, Jakarta.

Rifklefs, M.C. (1995), Sejarah Indonesia Modern. Terj. Dharmono Hardjowidjono, Gadjah Mada University Press, Yogyakarta.

Sudarto, Tyasno, (2008). Pendidikan Modern dan Relevansi Pemikiran Ki Hajar Dewantara, Majlis Luhur Persatuan Tamansiswa, Yogyakarta.

(2008). RM Suwardi Suryaningrat Bangsawan yang menjadi Bapak Bangsa, Majlis Luhur Persatuan Tamansiswa, Yogyakarta.

Soeroso, (1982). Bagaimana bermain Gamelan, Balai Pustaka, Jakarta.

Sumarsam, (2003), Gamelan, Pustaka Pelajar, Yogyakarta. 